\title{
Lucro e Prejuízo Sob a Perspectiva da Administração: Como os Resultados são Apresentados nos Relatórios de Administração?
}

\begin{abstract}
Resumo
Este artigo objetiva analisar como são apresentadas as informações textuais relativas aos resultados das empresas contidos nos Relatórios de Administração em períodos alternados de lucro e prejuízo. A fundamentação teórica foi pautada na teoria da agência e o gerenciamento de impressões. Adotou-se uma metodologia quali-quanti e a análise dos dados foi realizada por meio de testes estatísticos de comparação entre as médias das informações coletadas por meio da análise de conteúdo. Foram analisados Relatórios de Administração de 30 empresas listadas na BM\&FBovespa - que apresentaram lucro no ano de 2009 e prejuízo em 2010. As principais evidências encontradas na análise dos relatórios foram: i) diferença na quantidade de linhas e palavras no período de lucro para o de prejuízo; ii) em período de prejuízo é reduzida a ocorrência de termos que expressam esse resultado e aumento de destaque nos termos Ebitda e margem bruta; e iii) há indícios de desvio da atenção dos usuários dos resultados para outros indicadores por meio da seleção e repetição de termos financeiros, com redução na exposição dos resultados negativos e aumento dos indicadores positivos. Esses resultados apontam para um ambiente que reflete os problemas de assimetria informacional e que órgãos reguladores devem desenvolver políticas para monitorar a discricionariedade sobre as Demonstrações Financeiras que possam prejudicar os agentes do mercado.
\end{abstract}

Palavras-chave: Evidenciação. Relatórios de administração. Gerenciamento de impressões.
Luiz Henrique Fernandes Vargas

Mestre em Ciências Contábeis pela Universidade Federal do Espírito Santo e Assistente em Administração no Instituto Federal de Educação, Ciência e Tecnologia do Espírito Santo (IFES). Contato: Av. Vitória, 1729, Jucutuquara. Vitória-ES. CEP.: 29040-780.

E-mail: luizfvargas@gmail.com

José Elias Feres de Almeida Doutor em Controladoria e Contabilidade pela Universidade de São Paulo (USP) e Professor Adjunto II na Universidade Federal do Espírito Santo (UFES). Contato: Av. Fernando Ferrari, 514, CCJE, ED-VI, sl. 618, Goiabeiras. Vitória-ES. CEP.: 29075-910. E-mail: jose.e.almeida@ufes.br

\section{Elizeu Maria Junior}

Mestre em Ciências Contábeis pela Universidade Federal do Espírito Santo e Professor Assistente I na Universidade Federal do Espírito Santo. Contato: Av. Fernando Ferrari, 514, CCJE, ED-VI, sl. 618, Goiabeiras. Vitória-ES. CEP.: 29075-910. E-mail: elizeu.maria@ufes.br 


\section{Introdução}

A influência da discricionariedade dos usuários envolvidos no processo de elaboração das demonstrações contábeis não pode ser ignorada. Para Lopes e Martins (2005) os gestores, possuidores de mais informações que os usuários externos e investidores, utilizam a contabilidade para efetuar uma comunicação seletiva, não fornecendo todas as informações, mas aquelas que julgam ser mais convenientes ao próprio interesse. Esta assimetria informacional é originária da separação entre propriedade e controle, relatada no estudo seminal de Jensen e Meckling (1976), e se constituem a essência da teoria de agência.

As informações não obrigatórias sobre o desempenho e a situação da entidade, divulgadas pelas empresas de capital aberto, se encontram no relatório da administração e consistem em seção narrativa dos relatórios anuais publicados pelas empresas. Para Iudícibus (2010, p. 115) esses relatórios possuem evidenciações como planos de crescimento e expectativas do futuro da empresa e do setor, que embora normalmente enviesadas para o lado do "otimismo inconsequente", possuem relativa importância, desde que não auditadas em virtude desse viés.

A literatura vem apresentando pesquisas sobre as informações contidas nos relatórios de administração, bem como a disposição delas ou o uso de gráficos e imagens, como no estudo de Clatworth e Jones (2006) que discutem a tendência de serem usados dados de forma seletiva que apresentem informações favoráveis e uma visão positiva do desempenho corporativo. Observa-se, nesses relatórios, a caracterização de gerenciamento de impressões, ou seja, como a imagem corporativa poderia ser percebida pelos agentes econômicos. Para esses autores, a forma como a gestão das entidades utiliza informações voluntárias contidas nos relatórios anuais, como meio de fornecer uma visão para seus próprios interesses em relação ao desempenho, se caracteriza como uma área oportuna para pesquisas.

O relatório da administração traz a perspectiva da gestão sobre o desempenho apresentado pela empresa no período, com base nas informações contábeis divulgadas, bem como a forma como o ambiente externo afeta a empresa. Como o relatório da administração não segue um padrão, os executivos possuem discricionariedade para escolher não só as informações que devem compor esses relatórios, mas também termos, figuras e gráficos que podem ser utilizados em benefício próprio ou da empresa face as condições do ambiente em que estão inseridos. Em suma, os executivos podem gerar viés na interpretação dos dados e na escolha deles, além do modo como são relatados.

Destarte, considerando que a alta gestão das empresas pode adotar estratégias de divulgação que potencialize ou reduza assimetria de informações, a questão norteadora deste estudo é: Como são apresentadas nos relatórios de administração as informações referentes aos resultados anuais de empresas de capital aberto, listadas na BM\&FBovespa, nos períodos de lucro (2009) e prejuízo (2010)?

Assim, o objetivo deste estudo consiste em analisar como as informações relativas aos resultados anuais de empresas de capital aberto com ações negociadas na BM\&FBovespa são apresentadas nos relatórios de administração em relação ao período de lucro em 2009 e prejuízo em 2010.

O recorte metodológico adotado, analisando as empresas em 2009 e 2010 em momento de desempenho favorável e desfavorável, respectivamente, pode capturar a mudança do discurso das entidades vindo de períodos de lucro para um momento de prejuízo, além de aumentar a compreensão sobre a estratégia de divulgação.

Os resultados, de maneira geral, indicam a existência de gerenciamento de impressão nos relatórios analisados no que se refere à extensão dos textos destinados ao relato dos resultados contábeis, na quantidade de linhas do relatório como um todo e no uso de indicadores financeiros no período de prejuízo. Observamse ainda, neste mesmo período, indícios de abordagem seletiva na apresentação de termos que representam o resultado e o uso de ênfase por meio da repetição de termos financeiros ao longo dos textos.

Desse modo, este estudo reforça evidências nacionais e internacionais anteriores de que os problemas de assimetria informacional podem ser potencializados para amenizar a percepção dos usuários externos 
sobre eventuais prejuízos das empresas ou para reforçar a imagem corporativa em momentos de lucros. No ambiente brasileiro, com base nos resultados da amostra analisada, essas evidências mostram que agentes econômicos como investidores, credores, reguladores, analistas e acionistas minoritários precisam compreender as estratégias de divulgação da gestão das empresas para redução dos problemas de assimetria de informações que podem prejudicar o ambiente informacional e potencializar conflitos de agência.

Este estudo está dividido em cinco seções: i) introdução; ii) referencial teórico tratando da teoria de agência, do gerenciamento de impressões e de estudos anteriores; iii) metodologia utilizada no estudo; iv) análise qualitativa e quantitativa dos resultados; e v) considerações finais e sugestões de pesquisas futuras.

\section{Referencial Teórico}

\subsection{Teoria da Agência e Informações Contábeis}

A teoria econômica clássica, utilizada pelos teóricos no passado, tem por base os pressupostos de que as empresas atuam de forma racional, otimizam o lucro econômico e possuem apenas um dono, os quais conferem a ideia da não existência de conflitos de interesse. O surgimento da corporação moderna, em que a propriedade é separada da gestão, torna a teoria clássica distante da realidade empresarial, pois conflitos de interesse podem surgir neste novo tipo de empresa, entre acionistas e administradores. Assim, a teoria de agência vem romper com o paradigma presente na teoria econômica clássica ao afirmar a possibilidade de ocorrência destes conflitos (Lopes \& Martins, 2005, p. 28).

Jensen e Meckling (1976) afirmam que a teoria de agência tem por base os problemas da separação entre propriedade e controle. Para estes autores, a relação de agência ocorre pela contratação de uma pessoa; o agente, para a execução de serviço em nome de uma ou mais pessoas; o principal, de maneira que propicie ao agente a delegação de algum tipo de poder de decisão. Porém, considerando que ambas as partes visam à maximização de sua utilidade, existem boas razões para crer que o agente nem sempre agirá em favor dos interesses do principal, como afirmam os autores.

Os problemas de informação desenvolvidos na teoria de agência possuem ligação com a contabilidade uma vez que a informação contábil funciona como redutora dessa assimetria informacional, pois como os investidores não possuem o mesmo nível informacional, necessitam de instrumentos independentes que lhes possibilite avaliar a real situação da empresa (Lopes \& Martins, 2005, p. 31).

Conforme afirmam Lopes e Martins (2005, p. 55):

[...] como o envio de informações é discricionário, os administradores podem manipular as informações, fornecendo números com o objetivo de iludir os usuários a respeito da "real" situação da empresa. Por outro lado, é essa própria discricionariedade que possibilita que informações sejam levadas ao público.

Segundo Lopes, Ribeiro, Filho Pereira, Pederneiras, Silva e Santos (2010) a escolha da administração, quanto ao nível de disclosure nos relatórios de administração que a entidade apresenta, possui relação com o lucro contábil, sendo uma tendência natural por parte dos administradores fornecer mais informações quando os benefícios obtidos se apresentam superiores ao custo. A pesquisa destes autores permite a interpretação de que para os administradores traz mais benefícios ampliar a evidenciação de informações na ocorrência de lucro do que em prejuízo.

Complementarmente, afirmam Tessarolo, Pagliarussi e Luz (2010) que os estudos documentam a tendência por apropriar a causas internas efeitos positivos do resultado e a externas os efeitos negativos com o intuito de construir uma imagem da empresa que lhe seja favorável. Dessa maneira, esses estudos motivam a análise da parte textual dos relatórios anuais. 


\subsection{Gerenciamento de impressões}

Para Hendriksen e Breda (2009) a tendência de apresentar expectativas otimistas sobre a empresa nos relatórios de administração faz com que estes percam muito de seu significado. Por não ser auditado, este tipo de relatório possui informações passíveis de gerenciamento de impressões que, para Clatworthy e Jones (2006), consiste na tendência de indivíduos ou organizações usarem dados de forma seletiva para apresentar sinais favoráveis sobre os dados e uma visão positiva a respeito do desempenho corporativo. Para esses autores, embora este desejo da administração de apresentar esta visão positiva esteja presente em todas as empresas torna-se mais evidente, particularmente, quando o desempenho é ruim. As informações contidas nos relatórios de administração, parte integrante dos relatórios anuais, exprimem a visão dos gestores sobre a organização e podem apresentar viés positivo das informações.

No entanto, segundo Mendonça e Amantino-de-Andrade (2003, p. 40), "apesar de certas formas de gerenciamento de impressões serem usadas de maneira desonesta, outras envolvem a apresentação honesta e acurada dos atributos de sujeitos ou objetos [...]”. Assim, relatam os autores, uma forma de também entender o gerenciamento de impressões é a de um processo de comunicação com o qual se cria e envia mensagens para audiência com o objetivo da transmissão de determinada imagem ou impressão.

Para Patelli e Pedrini (2013) a dimensão ética do discurso existente nos relatórios apresentados pelas empresas é por vezes negligenciada na literatura, o que lhes preocupa em razão de evidências empíricas demonstrarem a importância destes relatórios nas decisões de investidores. Nesse estudo, ao analisarem as empresas americanas entre 2008 e 2009, os autores encontraram que existe ligação significativa entre o tom otimista e o desempenho financeiro. Concluem que no gerenciamento de impressões, o tom retórico é visto como forma de manipular para distrair a atenção do leitor sobre o desempenho passado e distorcer as expectativas futuras, pois na ação comunicativa o desempenho passado molda o tom retórico e traz informações úteis para prever as expectativas futuras.

De certa forma, a preferência por retratar-se favoravelmente por meio do gerenciamento de impressões figura como atributo humano compreensível, porém no contexto dos relatórios financeiros há o risco de deixar de sê-lo e violar a premissa básica de apresentar informações de forma neutra e imparcial nestes relatórios, afirmam Clatworthy e Jones (2006).

Existem incentivos, segundo Beattie e Jones (2002), para que os preparadores de relatórios corporativos manipulem ou pelo menos manipulem a impressão dos conteúdos transmitidos pelos relatórios de administração, sendo que, geralmente, destina-se à criação de uma visão mais favorável ao do desempenho do que realmente ocorre na empresa.

Nesse sentido, afirmam Clatworthy e Jones (2006), que a base do gerenciamento de impressões está nos gestores ofuscarem as falhas e destacarem os sucessos. Para Osma e Guillamón-Saorín (2011) há a seleção de informações de forma a distorcer a percepção dos leitores quanto às conquistas corporativas.

Aerts (2005) aponta a importância da informação, tanto para a relação agente-principal, quanto como dispositivo de comunicação sensível ao contexto. O autor destaca a discricionariedade do discurso das narrativas contábeis para a construção de apoio e convencimento dos investidores. Aponta, ainda, a existência de tendência à atribuição de resultados positivos às próprias ações e resultados negativos a fatores externos ou de oportunidade. Em seu estudo, o autor evidencia que em companhias abertas listadas há atitude oportunista na narrativa de divulgação, onde os textos são mais explicativos embora não mais extensos ou profundos. Há também construção de notícias positivas e maior grau de atitude defensiva para explicar resultados negativos.

Nesse caso, ocorre a ofuscação, que é uma medida discricionária da gestão que impacta em parte do comprimento adicional (tamanho) dos relatórios para tentar desviar a atenção das más notícias, tendo como causa a dificuldade em descrever perdas ou rendas transitórias. Ao relatar um desempenho fraco os gestores podem escrever relatórios mais longos e complexos tentando distrair os investidores ao discutir uma má notícia por meio de uma boa (Bloomfield, 2008). 
Segundo Beattie e Jones (2000) o gerenciamento de impressões pode ser dividido em números contábeis, que consiste na manipulação básica da mensuração e divulgação dos números e manipulação da apresentação, que se refere ao controle das informações apresentadas quanto ao seu conteúdo ou formatos, figuras ou gráficos. Os autores ainda afirmam que os gráficos além de coloridos e distrativos têm a capacidade de serem usados no processo de gerenciamento de impressões, onde a gestão pode destacar variáveis de desempenho que melhoraram e suprimir as que pioraram reforçando a impressão do desempenho que deseja transmitir.

Como forma de evidenciar a divisão e as estratégias adotadas para a apresentação das informações, no que tange ao gerenciamento de impressões, nas seções narrativas dos relatórios anuais, pode-se observar a identificação de sete abordagens de análise utilizadas por Brennan, Guillamón-Saorín e Pierce (2009) em seu estudo: 1) manipulação sintática, que consiste na análise da linguagem utilizada nas narrativas contábeis, onde há o uso da linguagem pelos gestores para o ofuscamento do desempenho, especialmente o negativo; 2) manipulação retórica, que também analisa a forma de ofuscar e encobrir o desempenho negativo; 3 ) atribuição de resultados, relacionada a analisar a atribuição de resultados positivos a fatores internos e negativos a fatores externos; 4) manipulação temática, que analisa o uso de temas positivos e negativos nas narrativas contábeis; 5) seletividade, que analisa como a gestão seleciona números de desempenho que retratem a empresa da melhor forma; 6) efeitos de apresentação visual (ênfase), analisa as três formas de ênfase utilizadas sendo a visual que trata da evidenciação de dada informação ao leitor como localização ou posicionamento, a repetição de um item e o reforço, em que é utilizado um qualificador junto ao termo apresentado; e 7) gerenciamento de impressões usando comparações de desempenho, em que a análise reside no estudo de pontos de referência e benchmarks nos relatórios.

Osma e Guillamón-Saorín (2011) evidenciam em seu estudo que fortes mecanismos de governança corporativa propiciam a inclusão de informações negativas nas divulgações e reduzem a incidência de gerenciamento de impressão nas divulgações narrativas, sendo as divulgações mais otimistas ligadas à expectativa de boa notícia no período seguinte. O gerenciamento de impressão, segundo os autores, figura como um mecanismo inserido na complexa estratégia de comunicação das empresas.

Em síntese, pode-se inferir que cada escolha carrega sinais para o mercado e dependendo da informação contábil divulgada a alta administração emite sua opinião potencializando aspectos positivos e amenizando os efeitos de indicadores financeiros negativos ou abaixo do esperado pelas expectativas do mercado. Todas essas escolhas aliadas a discricionariedade podem contribuir para aumentar ou reduzir a assimetria de informações que poderão afetar os problemas de agência.

\subsection{Pesquisas Anteriores Realizadas no Brasil}

Silva e Rodrigues (2006) ao pesquisarem relatórios de administração constataram que existe viés nas informações divulgadas nestes relatórios no sentido de poder prejudicar ou mesmo distorcer a percepção dos usuários das informações contábeis. Além disso, afirmam os autores que a administração tende a culpar o ambiente externo e a conjuntura econômica pelo desempenho inferior, e ser otimista quanto às reformas administrativas como prêmio pelo trabalho desenvolvido assumindo assim os bons resultados.

Ao analisar relatórios de administração de empresas listadas nos níveis de governança corporativa da Bovespa no ano de 2004, Gallon e Beuren (2007) evidenciaram que existe diferença entre os níveis de governança no que tange ao conteúdo de evidenciação dos itens do estudo. Concluíram que sentenças do tipo declarativas, em que a informação qualitativa é apresentada na forma exclusivamente descritiva, foram mais evidenciadas.

Silva, Rodrigues e Abreu (2007) verificaram a representação dos relatórios de administração como fonte de informação sobre as empresas. As conclusões desse estudo são de que empresas com crescimento do ativo e as de maior porte possuem relatórios mais extensos, ou seja, divulgam mais informações. Existiu influência do desempenho futuro na extensão do relatório e pessimismo nos relatórios de empresas 
que apresentaram ativo e patrimônio líquido menor do que no passado. Constataram, ainda, que maior volume de frases em relação à reforma administrativa foram apresentadas em relatórios otimistas e que os pessimistas tem sua atenção concentrada na conjuntura econômica.

Para verificar a existência de informações que indicam o risco financeiro de falência das empresas, Pagliarussi e Scotá (2009) aplicam no Brasil o modelo utilizado no ano de 2000 por Smith e Taffler, que consiste em analisar o conteúdo de forma objetiva, com a contagem de palavras; e subjetiva, orientada pelo significado em relação aos textos do estudo. Os resultados encontrados demonstram que os relatórios de administração são fontes importantes para prever o desempenho futuro das empresas.

Tessarolo, Pagliarussi e Luz (2010) pesquisaram o processo de justificação do desempenho organizacional em empresas brasileiras a partir da análise dos relatórios anuais nos anos de 2002 e 2003. Os autores concluem que os resultados apontam para a tentativa de criação de imagem positiva da empresa, mesmo na ocorrência de desempenho negativo em contexto externo favorável. No entanto, segundo os autores, empresas com desempenho positivo em um ano bom ou ruim culpam em proporção equivalente os efeitos negativos externos.

Guimarães (2011) pesquisou sobre a consistência existente nas mensagens transmitidas pelas seções narrativas dos relatórios anuais no tocante ao desempenho das empresas listadas na Bovespa no ano de 2009, aplicando pesquisa realizada em 2005 por Balata e Breton. A conclusão do estudo é de que existe conflito parcial nas informações, uma vez que não existe consistência total entre texto e números. Observou-se ainda nesse estudo que predominantemente as informações positivas são transmitidas pelas empresas com maior ênfase para pontos positivos e as situações negativas são minimizadas por meio de argumentos que as atenuem.

\section{Metodologia e Seleção da Amostra}

Este estudo tem como objeto de análise os relatórios de administração em períodos de lucro e de prejuízo das companhias abertas listadas na BM\&FBovespa. A estratégia adotada é quali-quanti, sendo a abordagem qualitativa utilizada para a análise dos resultados e relatos textuais, enquanto a abordagem quantitativa é utilizada para os testes estatísticos de comparação entre as médias das informações levantadas da análise de conteúdo da pesquisa documental.

Os dados foram interpretados por meio da análise de conteúdo, que para Bardin (2007) consiste em obter indicadores quantitativos ou que não permitam inferir conhecimentos das mensagens em relação às condições de produção e recepção por meio de um conjunto de técnicas de análise das comunicações que utilizam procedimentos sistemáticos e objetivos de descrição de conteúdos de mensagens. Dessa maneira, foi feito levantamento do volume de informações publicadas nos relatórios analisados que compreende a contagem do número de páginas, parágrafos, linhas, gráficos, tabelas, quadros, caracteres, conectivos e indicadores financeiros constantes nos relatórios de administração.

A população deste estudo corresponde à totalidade das empresas de capital aberto, com ações negociadas na BM\&FBovespa no ano de 2009 e de 2010, com seus Relatórios de Administração publicados e disponíveis no endereço eletrônico da Bolsa de Valores de São Paulo e com as informações financeiras disponíveis. A filtragem e seleção das empresas que compõem a amostra deste estudo, assim como a classificação setorial das empresas foram realizadas na base de dados Economática.

A amostra da pesquisa, conforme filtro estabelecido se restringe a 30 companhias abertas que reportaram lucro líquido nas demonstrações financeiras anuais do exercício de 2009 e prejuízo no exercício de 2010. Assim, foram analisados 60 relatórios de administração desses dois anos. Adotou-se neste estudo os termos desempenho favorável para representar as companhias que reportaram lucro líquido no exercício de 2009 e desempenho desfavorável para as companhias que reportaram prejuízo no exercício de 2010.

Em virtude dos arquivos dos relatórios objetos deste estudo estarem em 2009 no formato de documento de texto (doc) e em 2010 no formato aberto (pdf), o levantamento das informações ocorreu de forma manual. 
Os períodos (anos) estudados foram selecionados em virtude das alterações promovidas pela Comissão de Valores Mobiliários (CVM) por meio da Instrução CVM no 457 de 2007 que facultou às companhias abertas anteciparem a adoção da contabilidade internacional no Brasil (IFRS). Em função desta adoção das normas internacionais de contabilidade poder causar impactos no desempenho das empresas, verificaram-se também as informações presentes nos relatórios de administração a respeito de tal adoção e os possíveis efeitos sobre o resultado, bem como as empresas que justificaram seus desempenhos sobre eventos externos. Essas informações serão exploradas na seção de análise dos resultados.

As empresas que compõem a amostra deste estudo estão relacionadas no Figura 1 como segue:

\begin{tabular}{|l|l|l|}
\hline Banco Cruzeiro do Sul & Clarion & Lupatech \\
\hline Banco Panamericano & Oderich & Millenium \\
\hline BHG & Better & OGX \\
\hline Buettner & Lix da Cunha & Pettenati \\
\hline CEMEPE & Ferrovia Centro Atlântica & Rasip Agro Pastoril \\
\hline CELPA & General Shopping & Rede Energia \\
\hline CASAN & Gruçaí Participações & Refinaria de Petróleo Manguinhos \\
\hline CEEE-D & Hotéis Othon & RIMET \\
\hline Schlösser & J. B. Duarte & Springs \\
\hline Cia Melhoramentos SP & JBS & Tecnosolo \\
\hline
\end{tabular}

Figura 1. Empresas que compõem a amostra

\subsection{Hipóteses do Estudo}

Para o alcance do objetivo proposto foram verificadas, por meio do teste Wilcoxon-Mann-Whitney, de comparação de medianas, quatro hipóteses $(\mathrm{H} 1, \mathrm{H} 2, \mathrm{H} 3$ e H4) que são apresentadas a seguir. O uso deste teste não paramétrico se justifica em razão do tamanho da amostra desta pesquisa.

A forma de comunicação presente nos relatórios de administração, objetos desta pesquisa, em que consiste sua extensão, segue em linha ao estudo de Clatworthy e Jones (2006) que verificaram a não existência de diferença no comprimento (tamanho) dos relatórios de administração de empresas lucrativas e não lucrativas. Neste estudo utilizou-se as quantidades de páginas, parágrafos, linhas, gráficos, tabelas, quadros, caracteres e conectivos (porém, mas, todavia, no entanto, contudo e entretanto) presentes nos relatórios de administração para verificar a extensão dedicada à comunicação das empresas para o mercado nos períodos propostos. A análise da quantidade de conectivos busca observar o uso destes elementos como forma de justificar o resultado do período. Espera-se que exista diferença na extensão desses relatórios entre os períodos favorável e desfavorável alternadamente, assim:

H1: Há diferença estatisticamente significante em relação à extensão dos relatórios de administração nos períodos de desempenhos favorável e desfavorável.

Em relação ao uso de indicadores financeiros nos relatórios de administração Clatwothy e Jones (2006) rejeitaram a hipótese de que os relatórios do presidente de empresas rentáveis e não rentáveis contêm o mesmo número de indicadores financeiros por eles definidos como lucro, vendas, dividendos e lucro por ação. Em linha com estes autores, testa-se a similaridade de uso nos relatórios de administração, nos períodos favorável e desfavorável, dos seguintes indicadores financeiros: Resultado (lucro, lucro líquido, prejuízo, prejuízo líquido, resultado e resultado líquido), Lucro Bruto, Ebtida (Earnings Before Interest, Taxes, Depreciation and Amortization) e Margem Bruta. Espera-se que exista diferença no uso destes indicadores financeiros entre os períodos favorável e desfavorável nos relatórios estudados. Assim: 
H2: Há diferença estatisticamente significante no uso de indicadores financeiros nos relatórios de administração nos períodos de desempenhos favorável e desfavorável.

Busca-se encontrar, também neste estudo, se há diferença quanto à extensão dedicada à apresentação específica de desempenhos em períodos favorável e desfavorável nos relatórios de administração. Para isso foram utilizadas as quantidades de linhas e palavras dedicadas ao tema para verificar essa extensão. Esperase que exista diferença quantitativa na extensão dos textos dedicados especificamente aos desempenhos entre os períodos favorável e desfavorável, então:

H3: Há diferença estatisticamente significante entre a extensão dos textos dedicados especificamente à comunicação dos desempenhos favorável e desfavorável.

Ainda, em relação a esta forma de comunicação, este estudo verifica a possível existência de diferença de posicionamento da apresentação de desempenhos favorável e desfavorável nos relatórios de administração nos períodos propostos. Brennan, Guillamón-Saorín e Pierce (2008) afirmam que a localização ou posicionamento de divulgações podem depender se for um evento positivo ou negativo ou da divulgação se referir a resultados. Foram utilizados, neste estudo, para verificar este posicionamento, a quantidade de parágrafos e linhas existentes entre o início do relatório e o parágrafo destinado a divulgação do desempenho. Espera-se que exista diferença no posicionamento dos textos dedicados aos desempenhos entre os períodos favorável e desfavorável nos relatórios estudados, então:

H4: Há diferença estatisticamente significante na distância do início do relatório da administração e o texto dedicado à apresentação dos desempenhos entre os períodos de lucro e prejuízo.

A segunda parte deste estudo consiste em verificar, de forma qualitativa, como os desempenhos, favorável e desfavorável, são apresentados textualmente nos relatórios de administração e qual a ênfase utilizada pelo gestor na confecção dos relatórios nestes períodos. Busca-se, pela análise do investigador, verificar a existência de indícios de gerenciamento de impressões nos relatórios de administração no sentido do gestor apresentar em seu texto estratégias de ofuscamento dos resultados negativos e maior visibilidade dos resultados positivos ocorridos nos períodos do estudo.

\section{Evidências dos Relatórios de Administração}

\subsection{Análise dos dados e testes de hipóteses}

Inicialmente, nesta seção, é apresentado o resumo com as quantidades de páginas, parágrafos, linhas, tabelas, quadros, gráficos, caracteres e conectivos contidos no relatório da administração como um todo e sua variação do período de desempenho favorável (2009) para o de desempenho desfavorável (2010). Posteriormente são apresentadas estatísticas descritivas das informações levantadas e das relativas ao relato específico dos resultados dos períodos em análise. Na sequência, é apresentado o resultado do teste de comparação de medianas (Mann-Whitney) para verificar a existência de diferença estatística entre os períodos. 
Tabela 1

Dados gerais dos relatórios

\begin{tabular}{|c|c|c|c|c|}
\hline & $2009^{(a)}$ & $2010^{(a)}$ & Diferenç $^{(b)}$ & Variação \%(b) \\
\hline Páginas & 337 & 307 & (30) & $(8,90)$ \\
\hline Parágrafos & 2.376 & 2.177 & (199) & $(8,38)$ \\
\hline Linhas & 8.184 & 6.998 & $(1.186)$ & $(14,49)$ \\
\hline Tabelas e Quadros & 150 & 159 & 9 & 6,00 \\
\hline Gráficos & 75 & 105 & 30 & 40,00 \\
\hline Caracteres & 575.874 & 572.088 & (3.786) & $(0,66)$ \\
\hline Conectivos ${ }^{(c)}$ & 46 & 46 & 0 & 0,00 \\
\hline Resultado(d) & 101 & 71 & 30 & $(29,70)$ \\
\hline Lucro Bruto & 34 & 32 & 2 & $(5,88)$ \\
\hline EBITDA & 109 & 207 & 98 & 89,91 \\
\hline Margem Bruta & 15 & 32 & 17 & 113,33 \\
\hline
\end{tabular}

Nota: (a) Quantidades observadas para o total de empresas da amostra. Períodos de desempenho favorável (2009) e desfavorável (2010). (b) Entre parênteses percentuais negativos. (c) Conectivos utilizados nos textos para justificar resultados do período (porém, mas, todavia, no entanto, contudo e entretanto). (d) Como resultado consideram-se os termos: lucro, lucro líquido, prejuízo, prejuízo líquido, resultado e resultado líquido.

Observa-se, na Tabela 1, redução nominal da quantidade de espaço destinado à apresentação das informações relativas aos períodos de desempenho desfavorável em comparação ao período favorável. Das empresas que diminuíram o número de páginas, destaque para uma empresa do setor de Finanças e Seguros que em 2009 apresentou relatório contendo 20 páginas e em 2010 reduziu este número para 7 páginas, redução de 65\%. Por outro lado, uma empresa do setor de Petróleo e Gás aumentou o número de páginas de 9 para 16 do período de resultado financeiro favorável para o desfavorável, o que representa aumento de 77,78\%.

Entretanto, o número total de gráficos do período de desempenho favorável para o desfavorável apresentou um crescimento de $40 \%$, tendo como expoente empresa do setor de Alimentos e Bebidas, que em 2009 apresentou 3 gráficos em seu relatório e em 2010 passou a apresentar 17 gráficos. Observa-se, ainda, redução no uso de termos financeiros que expressam os resultados do período $(29,70 \%)$ nestes períodos e aumento nos termos Ebtida (89,91\%) e margem bruta (113,33\%).

Pela estatística descritiva pode-se supor que existe uma estratégia de divulgação do desempenho em diferentes condições da situação contábil-financeira das empresas. Ora para aumentar a explicação de uma mudança de resultados (redução de assimetria informacional) que, de repente, o mercado não esperava, ora para reduzir o grau de informação ao mercado (aumento de assimetria informacional). 
Tabela 2

Estatística descritiva dos dados gerais

\begin{tabular}{lrrrrrrrr} 
& \multicolumn{1}{c}{$\mathbf{2 0 0 9}$} & \multicolumn{5}{c}{$\mathbf{2 0 1 0}$} \\
\cline { 2 - 10 } & Média & Desv. Padrão & Mín. & Máx. & Média & Desv. Padrão & Mín. & Máx. \\
\hline Páginas & 11,23 & 10,18 & 1 & 38 & 10,23 & 8,11 & 1 & 28 \\
\hline Parágrafos & 79,20 & 68,98 & 5 & 242 & 72,57 & 58,23 & 6 & 216 \\
\hline Linhas & 272,80 & 232,23 & 18 & 945 & 233,27 & 163,96 & 13 & 577 \\
\hline Tabelas e Quadros & 5,00 & 8,75 & 0 & 43 & 5,30 & 8,89 & 0 & 40 \\
\hline Gráficos & 2,50 & 4,35 & 0 & 14 & 3,50 & 5,30 & 0 & 17 \\
\hline Caracteres & 19195,80 & 18736,08 & 1077 & 68289 & 19069,60 & 17188,07 & 878 & 63067 \\
\hline Conectivos & 1,53 & 2,93 & 0 & 15 & 1,53 & 1,81 & 0 & 7 \\
\hline Resultado & 3,37 & 4,41 & 0 & 21 & 2,37 & 3,48 & 0 & 15 \\
\hline Lucro Bruto & 1,13 & 3,61 & 0 & 19 & 1,07 & 2,92 & 0 & 15 \\
\hline EBITDA & 3,63 & 9,16 & 0 & 47 & 6,90 & 16,73 & 0 & 78 \\
\hline Margem Bruta & 0,50 & 1,31 & 0 & 6 & 1,07 & 3,17 & 0 & 16 \\
\hline
\end{tabular}

Nota: Períodos de desempenho favorável (2009) e desfavorável (2010).

A estatística descritiva das informações dos relatórios de administração como um todo, Tabela 2, demonstra que, em média, há redução de uma página na extensão do relatório de administração de um período a outro. Essa redução quando relacionada à quantidade máxima de páginas dos relatórios de administração observada nas empresas do estudo é de $26,32 \%$.

Por outro lado, os gráficos apresentam aumento de um período para o outro. Observou-se que, em geral, no período de prejuízo, as empresas focaram seus gráficos em receitas, despesas, margem, produção e lucro, sendo verificada a não existência de padrão nos tipos de gráficos e a não incidência, em algumas empresas, dos gráficos do resultado do período. Isso evidencia a tentativa de explicar o resultado ocorrido por variáveis que direcionam a atenção dos usuários desses relatórios para o que a alta gestão considera relevante para justificar o prejuízo ou para reduzir a atenção sobre ele. Na verificação dos relatórios de administração deste estudo puderam ser observadas que 56,66\% das empresas não utilizam gráficos em seus relatórios e 43,33\% não utilizam Tabelas e Quadros, o que justifica os desvios padrão maiores que as médias e o número mínimo ser zero para esses itens. Em linha com essas informações, pode-se observar a existência de redução das informações textuais contidas nos relatórios de administração e o aumento das informações ilustrativas pelo uso de gráficos.

Da mesma forma observa-se que, em média, os termos financeiros que remetem aos resultados do período apresentam redução na média do período de desempenho favorável para o desfavorável. No entanto, os termos Ebtida e Margem Bruta apresentaram aumento de um período a outro.

Tabela 3

Estatística descritiva dos relatos de resultados nos períodos

\begin{tabular}{lrcrrrrrrr} 
& \multicolumn{4}{c}{ 2009 } & \multicolumn{5}{c}{$\mathbf{2 0 1 0}$} \\
\cline { 2 - 9 } & Média & Desv. Padrão & Mín. & Máx. & Média & Desv. Padrão & Mín. & Máx. \\
\hline Linhas & 4,37 & 2,17 & 0 & 9 & 3,20 & 2,52 & 0 & 10 \\
\hline Palavras & 53,23 & 28,72 & 0 & 139 & 39,33 & 30,72 & 0 & 130 \\
\hline $\begin{array}{l}\text { Posição do } \\
\text { parágrafo }\end{array}$ & 37,33 & 47,27 & 0 & 221 & 30,17 & 34,54 & 0 & 160 \\
\hline Posição da linha & 134,73 & 169,24 & 0 & 709 & 103,60 & 111,72 & 0 & 488 \\
\hline
\end{tabular}

Nota: Períodos de desempenho favorável (2009) e desfavorável (2010). 
Na estatística descritiva contida na Tabela 3, referente ao relato específico do resultado do período contido nos relatórios de administração, foi possível observar o impacto das empresas que não apresentaram texto relativo ao resultado do período pela quantidade mínima de linhas, palavras, posição do parágrafo e posição da linha que apresentam valores zero. Na verificação dos relatórios de administração verificou-se que no período de desempenho favorável, duas empresas não apresentaram texto relativo ao resultado do período e que no período de desempenho desfavorável esse quantitativo aumenta para cinco empresas.

Em relação às posições dos textos utilizados para relatarem os resultados dos períodos em estudo, no que tange ao primeiro parágrafo e linha do relatório da administração até o parágrafo e linha que inicia o relato do resultado do período, nota-se que o período de desempenho favorável está mais distante, em média, do início do relatório. $\mathrm{O}$ mesmo se observa quanto à quantidade máxima encontrada na verificação dos relatórios. Nesse ponto há que se ressaltar que a quantidade total de páginas, linhas e parágrafos dos relatórios exercem influência sobre essas posições.

Tabela 4

\section{Resultados do teste Mann-Whitney}

\begin{tabular}{|c|c|c|c|}
\hline & & & \\
\hline & Médias 2009(a) & Médias 2010(a) & Prob $>|z|^{(d)}$ \\
\hline \multicolumn{4}{|l|}{ Resultados de H1 } \\
\hline Páginas & 11,23 & 10,23 & 0,4820 \\
\hline Parágrafos & 79,20 & 72,57 & 0,3182 \\
\hline Linhas & 272,80 & 233,27 & 0,0803 \\
\hline Tabelas e Quadros & 5,00 & 5,30 & 0,5209 \\
\hline Gráficos & 2,50 & 3,50 & 0,2404 \\
\hline Caracteres & $19.195,80$ & $19.069,60$ & 0,7343 \\
\hline Conectivos $^{(b)}$ & 1,53 & 1,53 & 0,2519 \\
\hline \multicolumn{4}{|l|}{ Resultados de H2 } \\
\hline Resultado(c) & 3,37 & 2,37 & 0,0162 \\
\hline Lucro Bruto & 1,13 & 1,07 & 0,4861 \\
\hline EBITDA & 3,63 & 6,90 & 0,0285 \\
\hline Margem Bruta & 0,50 & 1,07 & 0,0255 \\
\hline \multicolumn{4}{|l|}{ Resultados de H3 } \\
\hline Linhas & 4,37 & 3,20 & 0,0199 \\
\hline Palavras & 53,23 & 39,33 & 0,0321 \\
\hline \multicolumn{4}{|l|}{ Resultados de H4 } \\
\hline Posição do Parágrafo & 37,33 & 30,17 & 0,3595 \\
\hline Posição da Linha & 134,73 & 103,60 & 0,2575 \\
\hline
\end{tabular}

Nota: (a) Períodos de desempenho favorável (2009) e desfavorável (2010). (b) Conectivos utilizados nos textos para justificar resultados do período (porém, mas, todavia, no entanto, contudo e entretanto). (c) Como resultado consideramse os termos: lucro, lucro líquido, prejuízo, prejuízo líquido, resultado e resultado líquido. (d) Prob > $|z|$ corresponde à significância estatística do teste não-paramétrico para verificação de diferença entre duas medianas (Mann-Whitney).

Pode-se observar pela Tabela 4, considerando um nível de significância de 10\%, que existem evidências insuficientes para rejeitar H1 no que diz respeito à quantidade de páginas (Prob $>|z|=0,4820$ ), à quantidade de parágrafos (Prob $>|z|=0,3182$ ), à quantidade de tabelas e quadros (Prob $>|z|=0,5209$ ), à quantidade de gráficos (Prob $>|z|=0,2404)$, à quantidade de caracteres (Prob $>|z|=0,7343)$ e à quantidade de conectivos (Prob $>|z|=0,2519$ ). De outro modo, apesar de existirem diferenças nas médias e na análise textual, não foi possível identificar diferenças nesses padrões a 10\% de significância. 
Todavia, na mesma análise de $\mathrm{H} 1$, existem evidências para que $\mathrm{H} 1$ seja parcialmente rejeitada no que tange a verificação do número de linhas (Prob $>|z|=0,0803$ ), conforme resultados encontrados na Tabela 4. Assim, pode-se considerar que existem evidências de diferença entre a quantidade de linhas nos períodos de desempenho favorável e desfavorável.

Portanto, em relação à extensão dos relatórios de administração como um todo, os testes não são conclusivos levando a um resultado parcial de rejeição da hipótese H1. A rejeição parcial da hipótese se assemelha ao resultado encontrado por Clatworthy e Jones (2006) em que, ao contrário das expectativas, os autores não puderam concluir a existência de diferença entre os relatórios de empresas rentáveis e não rentáveis, no que diz respeito à propensão do gestor em destinar mais espaço e palavras na comunicação de seu sucesso do que seu fracasso, embora estes autores tenham analisado a extensão dos relatórios em relação à quantidade de palavras e páginas, que difere deste estudo.

Pela Tabela 4 observa-se, considerando um nível de significância de 10\%, que existem evidências para rejeitar $\mathrm{H} 2$ parcialmente no que diz respeito à quantidade do indicador resultado do período (Prob > $|z|=0,0162)$, à quantidade do indicador Ebtida (Prob $>|z|=0,0285)$ e à quantidade do indicador Margem Bruta (Prob $>|z|=0,0255)$. Em outras palavras, existem evidências de diferenças entre as quantidades de termos relacionados ao resultado do período (lucro, lucro líquido, prejuízo, prejuízo líquido, resultado e resultado líquido), à utilização dos indicadores Ebtida e Margem Bruta nos períodos de desempenho favorável e desfavorável. No entanto, em relação ao uso do indicador Lucro Bruto, considerando um nível de significância de 10\%, observa-se que existem evidências insuficientes para rejeitar H2 (Prob $>|z|=0,4861$ ).

A verificação de diferença significativa em relação aos comprimentos dos textos dedicados especificamente a comunicação dos desempenhos em períodos favorável e desfavorável foi elaborada pela hipótese $\mathrm{H} 3$, sendo que a expectativa é de que exista diferença nos comprimentos dos textos relativos aos resultados nos períodos em estudo. Verifica-se na Tabela 4 que existem evidências suficientes para rejeitar $\mathrm{H} 3$ no que se refere à quantidade de linhas (Prob $>|z|=0,0199)$ e à quantidade de palavras (Prob $>|z|=$ 0,0321). Assim, pode ser considerado que a quantidade de linhas e palavras destinadas à apresentação dos resultados muda nos períodos de desempenho favorável e desfavorável.

Quanto à verificação de diferença no posicionamento e localização do texto relativo à apresentação dos resultados nos períodos em análise, foi elaborada a hipótese $\mathrm{H} 4$, sendo que a expectativa é de existência de diferença na localização dos textos relativos ao resultado nos períodos em estudo. Pode-se observar na Tabela 4 que existem evidências insuficientes para rejeitar $\mathrm{H} 4$ no que diz respeito à posição do parágrafo (Prob $>|\mathrm{z}|=$ 0,3595) e a posição da linha (Prob $>|z|=0,2575)$. Logo, não é estatisticamente significante a diferença entre o posicionamento dos textos relacionados aos resultados nos períodos de desempenho favorável e desfavorável.

\subsection{Análise dos Relatos de Resultados dos Períodos}

Como forma de ampliar a discussão qualitativamente de como as informações referentes ao desempenho das empresas são apresentadas nos relatórios de administração, nesta parte do estudo apresentouse indícios de gerenciamento de impressões encontrados nesses relatórios, na amostra selecionada.

Embora muitos pontos possam ser observados na análise dos relatórios de administração, em relação à divulgação das informações financeiras, este estudo não tem a pretensão de esgotá-los tendo em vista a extensão e complexidade do assunto, sendo assim concentrou-se esta análise em três pontos: 1) a observação do uso de termos financeiros específicos no relatório da administração; 2) o formato como são apresentados os relatos do resultado dos períodos; e 3) o uso de termos financeiros variados para apresentação específica dos resultados dos períodos. Essa leitura qualitativa pode auxiliar os stakeholders das companhias abertas a se alertarem quando da leitura dos relatórios de administração.

Em relação ao primeiro ponto desta análise, pode-se observar pela leitura dos relatórios que os termos normalmente utilizados para representar os resultados do período são usados de forma diferenciada em períodos de desempenho favorável (2009) e em período desfavorável (2010). 
Os termos usuais para apresentação de resultados encontrados são lucro, lucro líquido, resultado líquido, prejuízo e prejuízo líquido, sendo estes os analisados nesta pesquisa. Agrupando estes termos mais usuais no termo resultado do período, verifica-se que em período com desempenho favorável foram observadas 46 ocorrências deste agrupamento de termos enquanto no período de desempenho desfavorável essas ocorrências reduziram para 33. Observa-se, portanto, queda de $28,26 \%$ na quantidade de ocorrências relacionadas ao resultado do período nos relatórios de administração como um todo.

Ainda, em relação aos termos financeiros utilizados nos relatórios de administração, é possível verificar a ocorrência de outros termos que representam desempenho, como a Margem Bruta e o Ebtida que apresentaram variação elevada de um período para o outro. Observou-se que nos períodos do estudo houve aumento de 100\% no uso do termo Margem Bruta do período de resultado financeiro favorável, com 9 ocorrências, para 18 ocorrências no período desfavorável. Em relação ao termo Ebtida foi observado aumento de $133 \%$ do período de resultado financeiro favorável perfazendo 51 ocorrências, e para o período de desempenho desfavorável 119 ocorrências observadas.

Essa estratégia pode ser observada, como exemplo, em uma empresa do setor de Alimentos e Bebidas que no ano de 2010, período de desempenho desfavorável, a empresa já apresenta no início da primeira página de seu relatório o seguinte parágrafo:

$\mathrm{O}$ ano de 2010 foi marcado por várias conquistas. Tendo como destaque a integração da Pilgrims Pride, em nossas operações Americanas, e do Bertin, em nossas operações no Mercosul. No campo operacional, é importante ressaltarmos o crescimento de nossas vendas, o qual ultrapassou $\mathrm{R} \$ 55$ bilhões, com um crescimento orgânico de 14,2\% e um Ebtida de R \$3,75 bilhões, saindo de uma margem Ebtida de 3,7\% em 2009 para $6,8 \%$ em 2010.

O termo Ebtida aparece em destaque no relatório da empresa como um todo, com variação positiva de um período a outro. No entanto, no ano anterior, em que a empresa apresentou desempenho favorável, o mesmo termo só vem a aparecer na $25^{a}$ página do relatório da administração do período, acompanhado do resultado.

Verifica-se, nos relatórios de administração das empresas que compõem a amostra deste estudo, que embora haja redução da quantidade total de páginas, parágrafos e linhas, e de suas médias, encontrados nas Tabelas 1 e 2, há aumento substancial do termo Ebtida e Margem Bruta nos períodos de resultado financeiro desfavorável. Além desse aumento entre períodos, a ocorrência do termo Ebtida no período desfavorável é mais expressiva do que os termos de resultado.

Essa escolha por parte dos gestores configura em sua estratégia de aplicar maior ênfase a outros termos que não o resultado para o período desfavorável mostrando, assim, valores positivos. A abordagem dos efeitos de apresentação visual descrita por Brennan, Guillamón-Saorín e Pierce (2009) pode ser observada nesta estratégia, ao enfatizar por meio da repetição os termos ao longo dos textos e o uso de comparações de desempenho por meio de pontos de referência nos relatórios.

O segundo ponto desta análise está relacionado à apresentação específica dos textos destinados a relatar o resultado dos períodos do estudo, em que a análise é efetuada no parágrafo onde os resultados são relatados. Verificou-se que no período de desempenho favorável, duas empresas não apresentaram texto relativo ao resultado do período e três apresentaram textos qualitativos, onde não relatam o valor do resultado do período. Esse quantitativo de empresas se altera no período de desempenho desfavorável, onde há aumento para cinco empresas que não apresentaram texto relativo ao resultado e redução para duas empresas que apresentaram textos qualitativos.

Como exemplo de texto qualitativo utilizado para apresentar o resultado do período financeiro favorável é possível observar o relatório da administração de uma empresa do setor Outros, voltada para a construção e engenharia, no ano de 2009: 
Lucratividade - o aumento do lucro líquido em relação ao exercício anterior, tem como base o incremento das atividades da companhia no campo da Construção, que em virtude da acirrada concorrência, numa estratégia de ampliação de market share, comprometeu em parte, margens de lucratividade. Desta forma os custos dos serviços prestados representaram 74,61\% da Receita Operacional, sendo que em 2008 esses custos representaram 78,71\% da Receita Operacional.

Para o período de desempenho desfavorável, como exemplo de texto qualitativo utilizado para apresentar o resultado, observa-se o relato de uma empresa do setor de Alimentos e Bebidas no ano de 2010:

Análise do Resultado Operacional do Período - o fechamento do ano de 2010 teve um resultado operacional negativo em decorrência dos problemas de bloqueios de embarque para a Argentina, devido as variações cambiais negativas e pela queda de preços praticados pelo setor no mercado interno.

Notou-se no período de desempenho desfavorável que há uma redução do número de linhas e consequentemente de palavras destinadas a apresentar o resultado, conforme Tabela 3. Foram observados para os períodos em estudo que $46,66 \%$ das empresas reduziram o número de linhas destinadas ao relato do resultado, enquanto 36,67\% mantiveram esse quantitativo e 16,66\% apresentaram aumento no número de linhas. Como exemplo dessa redução de número de linhas tem-se uma empresa do setor Outros, voltada para serviços hoteleiros, que ao reportar resultado favorável (2009) utilizou um total de 6 linhas e 71 palavras do relatório da administração para expressar seu resultado:

No período findo em 31 de dezembro de 2009, a BHG auferiu lucro líquido de R 2,6 milhões, basicamente em função do impacto de 3 principais fatores: (i) melhora no desempenho operacional da Companhia e crescimento da Rede de hotéis; (ii) equivalência patrimonial em negócios descontinuados no valor de R \$15,3 milhões; (iii) e reversão de provisão para redução ao valor de recuperação de ativos no valor de $\mathrm{R}$ \$,8 milhões.

No entanto, a mesma empresa ao reportar resultado desfavorável em 2010, altera sua estratégia de apresentação utilizando um total de 1 linha e 16 palavras do relatório da administração para expressar seu resultado:

No exercício findo em 31 de dezembro de 2010, a BHG apresentou prejuízo líquido de R\$ 6.172 mil.

Verifica-se, portanto, a estratégia do gestor em apresentar os resultados de maneira mais extensa em períodos de desempenho favorável e resultados ruins de modo mais objetivo em períodos de desempenho desfavorável. Portanto, o que se observa são indícios de gerenciamento de impressões como forma de diminuir a exposição do resultado em período de resultado negativo. Esses achados se confirmam na afirmação de Beattie e Jones (2000) de que existem evidências de que as empresas buscam melhorar notícias positivas e minimizar negativas.

Embora já se tenha tratado aqui do uso de termos nos relatórios de administração, neste último e terceiro ponto de análise, verificou-se o uso de termos diferenciados para apresentar o resultado do período especificamente. Evidenciou-se pela análise dos relatórios de administração, do período estudado, que os termos lucro líquido e prejuízo são substituídos por outros termos para representar o resultado, termos que em muitos casos não reportam o resultado líquido real do período.

Para o período de desempenho favorável, observa-se que 15 empresas apresentaram o termo lucro líquido, 50\% das empresas, para exprimir o resultado líquido do período, as outras 15 empresas da amostra, 50\%, apresentaram, além das que não apresentaram resultado, outros termos: resultado da atividade, resultado positivo, lucro (sem precisar qual tipo de lucro), resultado, resultado operacional, 
lucro líquido ajustado, receita operacional líquida e lucro bruto. Observou-se, em uma empresa do setor Outros, com atividades de exploração de imóveis, o termo lucro líquido ajustado apresentado no período de desempenho favorável para relatar o resultado do período:

Em 2009, a Companhia registrou um lucro líquido ajustado de $\mathrm{R} \$ 25,8$ milhões, ante a um prejuízo de $\mathrm{R} \$ 4,7$ milhões em 2008. Sem os efeitos da linearidade $\left.{ }^{*}\right)$, o lucro líquido ajustado do $4 \mathrm{~T} 09$ seria de R $\$ 10,2 \mathrm{mi}-$ lhões, representando um crescimento de $189,8 \%$ em relação ao $4 \mathrm{~T} 08$. (Grifo nosso)

Para uma empresa do setor Outros, voltada para serviços hoteleiros, observou-se, no período de desempenho favorável, o uso do termo receita operacional líquida para relatar o resultado do período:

A Receita Operacional Líquida apresentou um resultado 9\% superior no comparativo 2009 x 2008 tendo o RevPar ficado $15 \%$ acima do ano anterior. (Grifo nosso)

Ainda para o período de desempenho favorável evidenciou-se que o termo mais próximo utilizado por uma empresa do setor Têxtil para o resultado do período é o lucro bruto:

Lucro bruto - O lucro bruto decresceu 1,2\%, de R \$353,0 milhões, em 2008, para R \$348,9 milhões, em 2009. Resultado do esforço da Companhia na redução de custos e melhoria do mix de vendas. (Grifo nosso)

No período de desempenho desfavorável observou-se que 16 empresas apresentaram o termo prejuízo, 53,33\% das empresas, para exprimir o resultado líquido do período, as outras 14 empresas da amostra, 46,67\%, apresentaram, além das que não apresentaram resultado, outros termos: resultado da atividade, resultado negativo, lucro líquido no $4^{\circ}$ trimestre, resultado líquido ajustado, EBITDA, resultado positivo, resultado operacional e lucro bruto. Notou-se que uma empresa do setor Outros, com atividades de exploração de imóveis, apresentou o termo resultado líquido ajustado para relatar o resultado do período, no período de desempenho desfavorável:

No 4T10, a companhia registrou resultado líquido ajustado negativo em $\mathrm{R} \$ 14,4$ milhões, em comparação com o lucro líquido ajustado de R 7,6 milhões no 4T09. Em 2010, o resultado líquido ajustado negativo foi de $\mathrm{R} \$ 11,3$ milhões, comparado ao lucro líquido ajustado de $\mathrm{R} \$ 25,8$ milhões em 2009. (Grifo nosso)

Observou-se que uma empresa do setor Outros, voltada para serviços hoteleiros, no período de desempenho desfavorável não apresenta o termo prejuízo, e direciona o usuário ao termo EBITDA como forma de apresentar o resultado do período:

O Ebitda (Lucro Operacional antes das Despesas Financeiras, Impostos, Depreciação e Amortização) de 2010 foi de R \$9.267 evolução de 323\% em relação ao Ebitda do ano anterior que foi de R $\$ 2.044$. (Grifo nosso)

Para o período de desempenho desfavorável foi observado para uma empresa do setor Têxtil que o termo prejuízo não foi apresentado em seu relatório, direcionando o leitor para outras variáveis de resultados positivos como o lucro bruto:

Lucro bruto - O lucro bruto aumentou 14,2\%, de R $\$ 337,7$ milhões, em 2009, para $\mathrm{R} \$ 385,7$ milhões, em 2010, devido à combinação dos pontos já relatados. (Grifo nosso)

Verificou-se ainda que apenas uma empresa justificou seu desempenho desfavorável em função da adoção das normas internacionais de contabilidade, mais especificamente pela adoção do CPC - 29 Ativos Biológicos, e que outras duas empresas relataram que seus desempenhos desfavoráveis podem ter sido 
afetados por tal adoção. Nenhuma das empresas quantificou o impacto, ou possível impacto da adoção das normas internacionais de contabilidade sobre seus desempenhos e nem atribuíram à adoção destas mesmas normas seu desempenho favorável.

A partir das análises observadas, pode-se considerar que a possibilidade de gerenciamento de impressões ocorre por parte dos gestores pela discricionariedade que possuem em utilizar outros indicadores contábeis-financeiros que não representam o resultado líquido para apontar pontos positivos sob suas perspectivas ou para destacar fatores que alterem as expectativas externas a respeito das condições das organizações. A abordagem da seletividade descrita por Brennan, Guillamón-Saorín e Pierce (2009) pode ser observada nesta estratégia ao verificar que os gestores buscam evidenciar uma seleção de indicadores de desempenho para retratarem de melhor forma a empresa.

\section{Considerações Finais}

Este estudo analisou como as informações relativas aos resultados anuais de empresas de capital aberto com ações negociadas na BMFBovespa são apresentadas nos relatórios de administração em relação a período de lucro em 2009 e de prejuízo em 2010.

No que se refere à extensão dos relatórios, foram testadas quatro hipóteses para verificar como ocorrem as divulgações. Os resultados encontrados, no que se refere à análise quantitativa, indicam que, na amostra analisada, existe diferença da extensão dos textos destinados especificamente à apresentação do resultado entre os períodos de desempenho favorável e desfavorável, sendo que no período favorável os textos tendem a ser mais extensos.

Ao analisar os termos, indicadores financeiros, utilizados para apresentar o resultado do período, se observa diferenças estatisticamente significativas para Ebtida, margem bruta e os relacionados ao resultado (lucro, lucro líquido, prejuízo, prejuízo líquido, resultado e resultado líquido) de um período a outro. No entanto, como o termo lucro bruto não apresenta diferença estatisticamente significativa, a hipótese testada para o uso de indicadores financeiros como um todo foi parcialmente aceita.

Quanto à extensão dos relatórios de administração como um todo, os resultados indicam que a quantidade de páginas, parágrafos, tabelas, gráficos, quadros, caracteres e conectivos não apresentam diferença significativa entre um período e outro. No entanto, a quantidade de linhas apresenta diferença significativa, assim, a hipótese testada para a extensão do relatório da administração como um todo foi parcialmente aceita. Em relação ao posicionamento específico do texto destinado a apresentação do resultado não existe diferença significativa deste posicionamento entre os períodos do estudo.

A análise de conteúdo dos relatos textuais apresenta indícios de gerenciamento de impressões nos três pontos abordados nesta etapa do estudo. Os relatórios apresentam repetição de termos financeiros com ênfase maior para Ebtida e margem bruta, que apresentaram maior ocorrência no período de desempenho desfavorável do que no favorável. A redução do número de linhas e palavras utilizadas para expressar especificamente os resultados em período desfavorável em relação ao favorável pode ser visto como forma de diminuir a exposição dos prejuízos. Os termos financeiros utilizados para apresentar o resultado do período, especificamente, apresentaram indícios da abordagem seletiva, onde os gestores utilizam-se de indicadores de desempenho que melhor representem o resultado da empresa.

Como limitações do estudo, ressalta-se o tamanho da amostra e a do próprio pesquisador em relação a análise do conteúdo. A amostra foi obtida em virtude da metodologia utilizada para o alcance do objetivo deste trabalho de pesquisar as mesmas empresas em períodos de lucro (2009) e prejuízo (2010). Assim, os resultados e conclusões apresentados são restritos à amostra selecionada. É importante destacar que ter prejuízo pode fazer parte do negócio devido a mudanças conjunturais ou de reorganizações internas, e que outros indicadores financeiros podem representar mais adequadamente a realidade econômica das organizações nesses períodos. 
Sugere-se, para pesquisas futuras a análise do gerenciamento de impressões nos relatórios de administração com uma amostra maior de empresas, em períodos mais extensos e após a adoção completa do IFRS. A análise da literatura demonstrou que estudos em relação à utilização de gráficos financeiros, imagens e figuras são um campo em expansão.

\section{Referências}

Aerts, W. (2005). Picking up the pieces: impression management in the retrospective attributional framing of accounting outcomes. Accounting, Organizations and Society, 30(6), 493-517. doi: 10.1016/j. aos.2004.07.001.

Bardin, L. (2007). Análise de conteúdo (3a ed.). Lisboa: Edições 70.

Beattie, V. A. \& Jones, M. J. (2000). Impression management: the case of inter-country financial graphs. Jornal of International Accounting, Auditing \& Taxation, 9(2), 159-183. doi: 10.1016/S10619518(00)00030-6.

Beattie, V. A. \& Jones, M. J. (2002). Measure distortion of graphs in corporate reports: an experimental study. Accounting, Auditing \& Accountability Journal, 15(4), 546-564. doi: 10.1108/09513570210440595.

Bloomfield, R. (2008). Discussion of "annual report readability, current earnings, and earnings persistence". Journal of Accounting and Economics, 2(3), 248-252. doi: 10.1016/j.jacceco.2008.04.002.

Brennan, N., Guillamón-Saorín, E. \& Pierce, A. (2009). Methodological Insights: Impression management: developing and illustrating a scheme of analysis for narrative disclosures - a methodological note. Accounting, Auditing \& Accountability Journal, 22(5), 789-832. doi: 10.1108/09513570910966379.

Clatworthy, M. A. \& Jones, M. J. (2006). Diferential patterns of textual characteristics and company performance in the chairman's statement. Accounting, Auditing \& Accountability Journal, 19(4), 493511. doi: 10.1108/09513570610679100.

Gallon, A. V. \& Beuren, I. M. (2007). Análise do conteúdo da evidenciação nos relatórios da administração das empresas participantes dos níveis de governança da Bovespa. UnB Contábil, 10(2), 11-42.

Guimarães, T. N. (2011). Conflito de informaçães em relatórios anuais: um comparativo entre seções narrativas e o desempenho financeiro de empresas listadas na Bovespa. Dissertação de mestrado, Fundação Instituto Capixaba de Pesquisas em Contabilidade, Economia e Finanças, Vitória, ES, Brasil. Recuperado de http://www.fucape.br/_public/producao_cientifica/8/Disserta\%C3\%A7\%C3\%A3o\%20 Thiago\%20Neiva\%20Guimaraes.pdf

Hendriksen, E. S. \& Breda, M. F. van (2009). Teoria da Contabialidade (5a ed.). São Paulo: Atlas.

Instrução CVM n. 457, de 13 de julho de 2007 (2007). Dispõe sobre a elaboração e divulgação das demonstrações financeiras consolidadas, com base no padrão contábil internacional emitido pelo International Accounting Standards Board - IASB. Diário Oficial da União. Brasília, DF: Comissão de Valores Mobiliários-CVM.

Iudícibus, S. (2010). Teoria da Contabilidade (10ª ed.). São Paulo: Atlas.

Jensen, M. C. \& Meckling, W. H. (1976). Theory of the firm: Managerial Behavior, Agency Costs and Ownership Structure. Journal of Financial Economics, 3(4), 305 - 360. doi: 10.1016/0304-405X(76)90026-X.

Lopes, J. E. G., Ribeiro, J. F., Filho, Pereira, D. M. V. G., Pederneiras, M. M. M., Silva, F. D. C. da \& Santos, R. (2010). Um estudo da relação entre o lucro contábil e o disclosure das companhias abertas do setor de materiais básicos. Revista de Administração e Contabilidade da Unisinos - BASE, 7(3), 208-220.

Lopes, A. B. \& Martins, E. (2005). Teoria da contabilidade uma nova abordagem. São Paulo: Atlas. 
Mendonça, J. R. C. \& Amantino-De-Andrade, J. (2003). Gerenciamento de impressões: em busca de legitimidade organizacional. Revista de Administração de Empresas - RAE, 43(1), 36-48.

Osma, B. G. \& Guillamón-Saorín, E. (2011). Corporate governance and impression managemente in annual results press releases. Accounting, Organizations and Society, 4(5), 187-208. doi: 10.1016/j. aos.2011.03.005.

Patelli, L. \& Pedrini, M. (2013). Is the optimism in CEO's letters to shareholders sincere? Impression management versus communicative action during the economic crisis. Journal of Business Ethics, 1(10), 1-16. doi: 10.1007/s10551-013-1855-3.

Plagliarussi, M. S. \& Scotá, R. (2009). O uso do disclosure narrativo em relatórios anuais corporativos para inferência da continuidade das empresas. Revista de Contabilidade e Organizações - FEARP/ USP, 3(5), 3-24.

Silva, C. A. T. \& Rodrigues, F. F. (2006, julho). Análise das variáveis que influenciam as informações divulgadas nos relatórios da administração das companhias abertas brasileiras: um estudo empírico nos anos de 2001 a 2003. Anais do Congresso USP de Controladoria e Contabilidade, São Paulo, SP, Brasil, 6.

Silva, C. A. T. \& Rodrigues, F. F. (2006). Análise das variáveis que influenciam as informações divulgadas nos relatórios da administração das companhias abertas brasileiras: um estudo empírico nos anos de 2001 a 2003. Anais do Congresso USP de Controladoria e Contabilidade, São Paulo, SP, Brasil.

Silva, C. A. T., Rodrigues, F. F \& Abreu, R. L. (2007). Análise dos relatórios de administração das companhias abertas brasileiras: um estudo do exercício social de 2002. Revista de Administração Contemporânea - RAC, 11(2), 71-92.

Tessarolo, I. F., Pagliarussi, M. S. \& Luz, A. T. M. (2010). The justification of organizational performance in annual report narratives. Brazilian Administration Review - BAR, 7(2), 198-212. 